TAIRO BATISTA ESPERANÇA

\title{
MARXISMO E DIREITO ELEITORAL: elementos para uma crítica
}

\author{
Dissertação de Mestrado \\ Orientador: Professor Associado Dr. Marcus Orione Gonçalves Correia
}

UNIVERSIDADE DE SÃO PAULO

FACULDADE DE DIREITO

São Paulo-SP

2017 


\section{TAIRO BATISTA ESPERANÇA}

\section{MARXISMO E DIREITO ELEITORAL: elementos para uma crítica}

Dissertação apresentada à Banca Examinadora do Programa de Pós-Graduação em Direito, da Faculdade de Direito da Universidade de São Paulo, como exigência parcial para obtenção do título de Mestre em Direito, na área de concentração de Direitos Humanos, sob a orientação do Professor Associado Dr. Marcus Orione Gonçalves Correia.

UNIVERSIDADE DE SÃO PAULO

FACULDADE DE DIREITO

São Paulo-SP 
Autorizo a reprodução e divulgação total ou parcial deste trabalho, por qualquer meio convencional ou eletrônico, para fins de estudo e pesquisa, desde que citada a fonte.

\section{Catalogação da Publicação}

Serviço de Biblioteca e Documentação

Faculdade de Direito da Universidade de São Paulo

Esperança, Tairo Batista

Marxismo e Direito Eleitoral: elementos para uma

crítica / Tairo Batista Esperança ; orientador Marcus Orione

Gonçalves Correia -- São Paulo, 2017.

$116 \mathrm{f}$.

Dissertação (Mestrado - Programa de Pós-Graduação em Direitos Humanos) - Faculdade de Direito, Universidade de São Paulo, 2017.

1. Voto. 2. Direito. 3. Capitalismo. 4. Brasil. 5. Marxismo. I. Correia, Marcus Orione Gonçalves, orient. II. Título. 
Nome: ESPERANÇA, Tairo Batista

Título: Marxismo e Direito Eleitoral: elementos para uma crítica

Dissertação apresentada à Faculdade de Direito da Universidade de São Paulo como exigência parcial para obtenção do título de Mestre em Direito.

Aprovado em:

Banca Examinadora

Prof. Dr.

Instituição:

Julgamento:

Assinatura:

Prof. Dr.

Instituição:

Julgamento:

Assinatura:

Prof. Dr.

Instituição:

Julgamento:

Assinatura: 
Dedico este trabalho à minha esposa, Tais Lima de Deus, por todo o amor, admiração e respeito cultivados nesses anos de vida conjunta. 


\section{AGRADECIMENTOS}

Gostaria de agradecer, primeiramente, à minha esposa, Tais Lima de Deus, pelo companheirismo e carinho durante a elaboração deste trabalho. Nos momentos mais difíceis, o seu apoio foi o fundamento para que eu seguisse em frente. Agradeço, em especial, pela paciência. Não foram poucos os dias em que estive indisponível. Espero que estas linhas, de alguma forma, sirvam como retribuição pela minha ausência.

Agradeço aos meus pais, Antonio Carlos Esperança e Gláucia Joana Batista; ao meu irmão, Muriel Batista Esperança; e aos demais membros das minhas famílias materna e paterna. Aos dois primeiros, pelo investimento desde cedo em minha instrução e pelos valores que me foram transmitidos. A todos, pela convivência sempre tão sólida e prazerosa.

Quero agradecer também à Paula Licursi Prates pelo apoio no percurso desta dissertação. Nossas conversas foram a fonte da minha estabilidade e disciplina nesse período. Certamente, o resultado não teria sido o mesmo sem a sua ajuda.

Faço um agradecimento especial ao Thiago Clemente do Amaral pelos almoços, hipóteses de trabalho e frustrações que compartilhamos. Tenho sorte em ter um grande amigo como este, com quem sempre pude e poderei contar.

Deixo também meu agradecimento aos amigos de Birigui, minha cidade natal, pelos momentos de descontração, ainda que à distância. São eles: André Luiz Bonifácio, Arnaldo Querino, Artur Polizel, Aryel Fernandes, Cássio Sandrigo Santini, Evaristo Luiz Momesso Neto, Guilherme Eliseu Martins e Luiz Henrique Moimaz Soares. Sou grato por este vínculo importante que mantemos.

Do mesmo modo, agradeço ao Ronny Leal dos Santos, à Imainara Cairolli, ao Aleksei Neves e ao Pablo Biondi pela amizade e pelo apoio sempre presentes.

Agradeço ao meu orientador, Marcus Orione Gonçalves Correia, pelos ensinamentos e pela paciência na condução deste trabalho. Foram muitas as dúvidas, reuniões e revisões. Em situações complexas, nas quais as buscas bibliográficas não pareciam apontar para uma conclusão, os seus direcionamentos foram essenciais para a continuação da pesquisa. 
Agradeço aos companheiros e companheiras do Partido Socialista dos Trabalhadores Unificado (PSTU), assim como a alguns dos militantes que recentemente deixaram nossas fileiras, pela camaradagem e pelo aprendizado. Como são muitos, não os poderei citar individualmente. Entretanto, gostaria de registrar, dentre eles, minha especial gratidão aos advogados e estudantes de direito, com os quais tive muito contato nos últimos anos. O exercício jurídico é sempre um desafio para nós, trotskistas. Nas várias atividades e reuniões que fizemos, tive a oportunidade de compreender, na prática, a relação do direito com o capitalismo e a exploração entre as classes.

Deixo, por fim, meu reconhecimento aos professores e estudantes do Coletivo "Direitos Humanos, Centralidade do Trabalho e Marxismo" (DHCTEM). Novamente, não farei referência a cada um, mas gostaria que todos se sentissem contemplados. Os textos e debates que tivemos, nesse espaço tão raro à academia, foram fundamentais para a minha formação teórica marxista. 
O direito como forma não pode ser captado fora das suas mais restritas definições. Ele existe apenas nos seus pares de opostos: direito objetivo, direito subjetivo; direito público, direito privado etc. Porém, todas estas distinções fundamentais aparecerão ligadas mecanicamente à formulação principal se esta for estabelecida de maneira a abarcar todas as épocas e todos os estágios que não conheceram, de nenhum modo, as mencionadas oposições.

Apenas a sociedade burguesa capitalista cria todas as condições necessárias para que o momento jurídico esteja plenamente determinado nas relações sociais.

\section{E. B. Pachukanis}




\section{RESUMO}

ESPERANÇA, Tairo Batista. Marxismo e Direito Eleitoral: elementos para uma crítica. 2017. 116 f. Dissertação (Mestrado) - Faculdade de Direito, Universidade de São Paulo, São Paulo, 2017.

Este trabalho tem como objeto demonstrar que o voto no Brasil passa se exercer como direito em correspondência com a consolidação do modo de produção capitalista. No intervalo histórico anterior, devido às condições materiais existentes, ele se fundamenta em superestruturas estranhas à forma jurídica, como a religião e a política. Nosso pressuposto teórico é o marxismo, com seu método materialista, histórico e dialético. Com base nas elaborações inauguradas por Marx e expandidas por Pachukanis, consideramos o direito um fenômeno específico do capitalismo, que consiste na relação de equivalência entre indivíduos abstraídos como sujeitos de direito. Essa demonstração será feita por meio da comparação das leis brasileiras sobre matéria eleitoral na história. A partir de uma seleção de teses sobre a colonização e a transição para o capitalismo no país, serão delimitados dois períodos de referência: um reconhecidamente pré-capitalista, que abrange a colônia e a maior parte do império; e outro de estabelecimento desse modo de produção, entre as vésperas da abolição da escravatura e fins da década de cinquenta. Como resultado, veremos que as legislações em cada intervalo evidenciam a constatação proposta. Entre outros indícios legais, existiam liturgias solenes e critérios políticos para a prática do sufrágio antes do capitalismo. Durante a sua consolidação, as restrições são, com poucas exceções, abandonadas. O voto, então, passa a se exercer como forma jurídica, com fundamento na livre e igual manifestação de vontade pelos eleitores.

Palavras-chave: Voto. Direito. Capitalismo. Brasil. Marxismo. 


\begin{abstract}
ESPERANÇA, Tairo Batista. Marxism and Electoral Law: elements for a critique. 2017. 116 f. Dissertation (Master) - Faculty of Law, University of São Paulo, São Paulo, 2017.

This paper aims to demonstrate that the vote in Brazil starts to be exercised as a right in correspondence with the consolidation of the capitalist mode of production. In the previous historical interval, due to the existing material conditions, it is based on superstructures extraneous to the legal form, such as religion and politics. Our theoretical assumption is Marxism, with its materialistic, historical and dialectical method. Based on the elaborations developed by Marx and expanded by Pachukanis, we consider law a specific phenomenon of capitalism, which consists in the relation of equivalence between individuals abstracted as legal subjects. This demonstration will be done by comparing the Brazilian electoral laws in history. From a selection of theses on colonization and the transition to capitalism in the country, two periods of reference will be delineated: an admittedly pre-capitalist period, covering the colony and most of the empire; and another of establishment of this mode of production, between the eve of the abolition of slavery and the end of the fifties. As a result, we will see that the legislations at each interval evidence the proposed finding. Among other legal evidences, there were solemn liturgies and political criteria for the practice of suffrage before capitalism. During the consolidation of this mode of production, the restrictions are, with few exceptions, abandoned. The vote, then, is exercised as a legal form, based on the free and equal manifestation of will by the voters.
\end{abstract}

Keywords: Vote. Law. Capitalism. Brazil. Marxism. 


\section{SUMÁRIO}

1. INTRODUÇÃ̃

2. FORMA JURÍDICA E CAPITALISMO ................................. 13

3. TEORIAS DA COLONIZAÇÃ̃

3.1. Caio Prado Júnior: a colonização e o seu sentido histórico ..................... 27

3.2. Fernando Novais: a colonização como projeção do capital mercantil na economia 38

3.3. Jacob Gorender e o modo de produção escravista colonial........................ 44

3.4. Fragoso e Florentino: a ruptura do sentido da colonização com base na realidade econômica da colônia.................................................... 50

3.5. Costa e Pires: o capital escravista-mercantil como hipótese explicativa........... 55

3.6. Conclusões.................................................................... 59

4. TRANSIÇÃO PARA O CAPITALISMO NO BRASIL $\ldots . . . \ldots \ldots \ldots \ldots \ldots \ldots \ldots . . . . . .61$

4.1. João Cardoso de Mello: a transição capitalista como obra dos cafeicultores

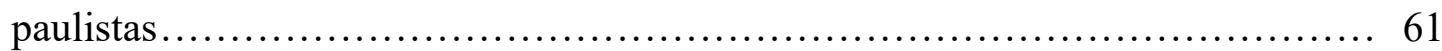

4.2. Gorender e Décio Saes: o capitalismo e a revolução social antiescravista brasileira 72

4.3. Conclusões .......................................................... 80

5. DIREITO, VOTO E HISTÓRIA............................................ 82

5.1. O voto no período pré-capitalista brasileiro ................................. 82

5.2. O voto como direito e o capitalismo no Brasil................................ 97

6. CONCLUSÕES.................................................................. 104

REFERÊNCIAS................................................................ 107 


\section{INTRODUÇÃO}

O objetivo deste trabalho é o de demonstrar que o exercício do voto como direito em nossa história se dá em correspondência com a consolidação do capitalismo no país. Em outros termos, queremos constatar que, com o estabelecimento desse modo de produção, o sufrágio se desvincula de superestruturas estranhas à forma jurídica, como a religião e a política, e passa a se dar entre indivíduos tornados sujeitos.

No intervalo entre as vésperas da abolição da escravatura e fins da década de cinquenta, que se pode fixar como referência aproximada para a transição ao capitalismo no Brasil, existiram mudanças legislativas que dão indícios suficientes dessa transformação. O sufrágio, com poucas exceções, estende-se igualmente a todos os indivíduos; garantem-se métodos para a preservação da equivalência entre suas vontades, como o sigilo do voto; e tornam-se dispensáveis as fórmulas solenes e religiosas, antes obrigatórias nas assembleias eleitorais. Diferentemente do que se verifica no período précapitalista, o voto passa a se fundamentar na observância da livre e igual manifestação de vontade dos eleitores. Tais valores, como se verá, têm como base a subjetividade jurídica, ou seja, a relação dos indivíduos na condição contraditória de sujeitos-mercadoria.

Esse escopo parte de alguns pressupostos. O referencial que adotamos é o marxista, com o seu método materialista, histórico e dialético. Entendemos que o direito é um fenômeno específico do modo de produção capitalista, conforme as elaborações inauguradas por Marx n'O Capital e expandidas, posteriormente, por Pachukanis no seu “Teoria Geral do Direito e Marxismo". São também base para esta pesquisa os desenvolvimentos teóricos posteriores sobre a forma jurídica de autores como Bernard Edelman e Márcio Bilharinho Naves.

Como justificativa para a escolha do nosso objeto, coloque-se que a prática do sufrágio remonta aos primeiros anos da colonização de nossas terras e que existe vasta produção legislativa e bibliográfica a respeito. No aprofundamento desta pesquisa, pode-se perceber que as características do voto no pré-capitalismo brasileiro, assim como a passagem para o seu exercício como direito, poderiam ser demonstradas com recurso à legislação do período. De todo modo, deve-se esclarecer que ele foi escolhido como um 
exemplo. Outros fenômenos sociais também adquirem a forma jurídica com o desenvolvimento do capitalismo.

Quanto ao itinerário deste trabalho, ele terá o seguinte formato. No primeiro capítulo, serão expostos os fundamentos teóricos da pesquisa. Com base neles, demonstraremos que o direito é um fenômeno histórico e capitalista, na medida em que consiste na relação de equivalência entre sujeitos de direito. $\mathrm{O}$ processo de abstração e mercantilização do trabalho humano, próprio desse modo de produção, é a base material para o desenvolvimento da subjetividade e da forma jurídicas.

Na segunda e na terceira partes, desenvolveremos uma seleção de teses sobre a colonização e a consolidação do capitalismo no país. Esse é um debate em aberto na historiografia e que não se pretende exaurir. Desse modo, em ambos os pontos, usaremos o método de escolher, dentro dos pressupostos de que partimos, um conjunto de autores representativo da discussão teórica existente, ainda que suas fundamentações e resultados tenham diferenças entre si. Fala-se de nomes como Caio Prado Júnior, Jacob Gorender, João Cardoso de Mello e Décio Saes. Com base nos pontos em comum de suas teorias, delimitaremos, mesmo que de forma aproximada, dois intervalos de nossa história: um reconhecidamente pré-capitalista e outro de consolidação desse modo de produção.

No último capítulo, trabalharemos com as legislações sobre o exercício do voto em nossa história. Em primeiro lugar, constataremos, com base nas evidências desses diplomas legais, que, no período anterior ao advento capitalismo, o sufrágio se baseou em práticas solenes e religiosas, bem como se deu com a exclusão de indivíduos por critérios fornecidos pela superestrutura política. Em segundo, que esses fundamentos extrajurídicos foram abandonados no intervalo de estabelecimento do capitalismo no país. Existem indícios suficientes em nossa legislação histórica para ambas as demonstrações.

Nas conclusões, por fim, serão retomados como síntese os resultados deste trabalho. Faremos, também, uma avaliação sobre o percurso realizado, além de breves observações sobre a relação entre o voto, a forma jurídica e o capitalismo. 


\section{CONCLUSÕES}

Em sede de conclusões, cabe-nos, primeiramente, retomar os resultados que foram alcançados no capítulo anterior. Eles são a síntese do nosso objeto. Como demonstrado, as leis eleitorais brasileiras indicam que o voto passa a se exercer como forma jurídica em correspondência com a consolidação do capitalismo no país. No intervalo adotado como referência para essa transição, ainda que com algumas exceções, ele se torna universal, secular e garantido em termos de isonomia entre os eleitores. No mesmo sentido, nossa legislação evidencia que, no período anterior, dada a ausência da subjetividade jurídica, o sufrágio encontrou fundamento em superestruturas estranhas ao direito. Foram vários os preceitos a estabelecer fórmulas litúrgicas e critérios políticos para o exercício do voto. Como se vê, o sufrágio assume a forma jurídica em correlação com as condições específicas da sociedade.

Essa conclusão corresponde ao que se expôs no início deste trabalho quanto à especificidade histórica capitalista da forma jurídica. Nesse momento, demonstrou-se que o direito é a relação de equivalência subjetiva entre os indivíduos, abstraídos como sujeitos em correlação com as condições materiais desse modo de produção. Como se viu, a separação do produtor dos seus meios de trabalho e a abstração de sua atividade laboral, que impõem a troca como relação de produção, são o que consolida a referida medida de igualdade entre os seres humanos. Subjetividade jurídica, subsunção material do trabalho ao capital e intercâmbio mercantil são fenômenos que dependem uns dos outros reciprocamente. Nesse sentido é que o voto, como forma jurídica, só passa a ter existência com o desenvolvimento do capitalismo. Não há relação subjetiva de igualdade em que ele possa se alicerçar no momento histórico anterior.

Quanto ao período de consolidação do capitalismo brasileiro, viu-se que o debate teórico está longe de ser pacificado. Dados os limites deste trabalho, não se teve a pretensão, nesses capítulos, de exaurir as teses existentes, ou de escolher uma para a refutação das demais. Elas precisaram ser tomadas, na medida do possível, como um pressuposto da pesquisa, e não como seu objeto. Com base nessas considerações, decidiuse apresentar um conjunto delas que fosse representativo da discussão em curso, e que permitisse, sob o prisma teórico da forma jurídica, que chegássemos a conclusões, ainda 
que conflitantes quanto ao período, sobre a relação entre voto, direito e capitalismo no país. Com esse procedimento, alcançaram-se definições históricas indispensáveis ao nosso objeto: estabelecemos o caráter pré-capitalista de nossa sociedade entre a colônia e o império; e fixamos o momento da transição para esse modo de produção, ainda que com alguma margem de indeterminação quanto às datas. Com base nelas, como visto, é que se fez a análise histórica da legislação eleitoral brasileira.

O exemplo escolhido como objeto deste trabalho, o do exercício do voto, revelou-se bom para a demonstração do nexo existente entre a forma jurídica e o modo de produção capitalista. Como visto, ele se dá desde o início da colonização e existe grande produção legislativa e bibliográfica a seu respeito. No mesmo sentido, revelou-se acessível expor a sua desvinculação para com as esferas da religião e da política. Bastou, para tanto, um estudo legislativo comparado. O sufrágio, mesmo sendo um exemplo do direito público, com suas construções "grotescas", como diz Pachukanis (1988, p. 63), foi suficiente para confirmar a especificidade histórica do direito. Permitiu-nos, também, apresentar as suas manifestações "antediluvianas" no período pré-capitalista de nossa história.

De certo, porém, ele não foi um exemplo perfeito, como demonstra a restrição ao voto do analfabeto. Essa vedação teve um movimento atípico e que destoou das demais apresentadas. Teve início, como visto, com a Lei Saraiva (1881), ou seja, já no período considerado como de consolidação do capitalismo brasileiro; e permaneceu em vigência até 1985 , data posterior ao seu término e muito próxima do atual regime constitucional. Os analfabetos seguem, até a atualidade, proibidos de assumir cargos eletivos. Várias hipóteses podem justificar esse e outros fenômenos similares de nossa história jurídica. É possível que essa proibição seja um elemento divergente em meio a um conjunto mais amplo, como a "exceção que confirma a regra"; ou, ainda, uma especificidade da transição tardia do capitalismo brasileiro. Quaisquer que sejam as teses que se adotem, elas merecem, certamente, aprofundamento teórico e novas pesquisas. Eis um tema em aberto, portanto: explicar as eventuais singularidades históricas da forma jurídica no país e sua possível relação com o desenvolvimento do nosso capitalismo.

Outro ponto a se destacar é que o voto como direito não é sinônimo de democracia em seu exercício. Essa é uma relação equivocada e que foge à consideração materialista dos fenômenos sociais. Como visto, a forma jurídica existe a partir da 
abstração dos indivíduos em sujeitos equivalentes. Ela tem base material nas forças produtivas capitalistas e na comercialização do trabalho, tornado abstrato. O objetivo desta pesquisa foi o de constatar que o sufrágio assume tal forma em função dessas condições. Fazer a sua relação com um valor "universal", como a democracia, é uma espécie de idealismo estranho ao método materialista, histórico e dialético a que nos propusemos.

Demonstração disso se encontra, como de costume, na História. As mudanças legislativas apresentadas, que evidenciam o acolhimento da forma jurídica pelo voto, em geral não coincidem com períodos considerados “democráticos" em nosso país. Como exposto, o voto se estende aos ex-escravos em 1888, logo antes da República Velha e de suas conhecidas práticas de controle oligárquico das eleições. As mulheres passam a exercê-lo em 1932, às vésperas do Estado Novo, período no qual inexistiram partidos políticos e sequer eleições de "fachada". Adota-se a cédula única oficial poucos anos antes do golpe militar de 1964. Como se vê, não há relação entre a prática do voto como direito e a consolidação dos períodos "democráticos" brasileiros.

Coloque-se, por fim, que o fato de o voto se exercer universalmente e em condições de isonomia não significa que ele seja um instrumento de transformação estrutural da sociedade. Como forma jurídica, ele tem especificidade histórica capitalista; serve, assim, à manutenção desse modo de produção. Em paralelo com Edelman (1976), podemos dizer que as pessoas são livres para votar como o são para se vender em troca de um salário. É uma liberdade que, ao final, só se exerce pela redução ao seu oposto, pela sujeição. 


\section{REFERÊNCIAS}

ALAPANIAN, Silva. A crítica marxista do direito: um olhar sobre as posições de Evgeni Pachukanis. In: NAVES, Márcio Bilharinho (Org.). O discreto charme do direito burguês: ensaios sobre Pachukanis. Campinas: Unicamp, Instituto de Filosofia e Ciências Humanas, 2009. p. 21-43. (Coleção Ideias nº 8)

ALVARÁ de 12 de novembro de 1611. Em que se declarou a fórma de fazer as eleições de Juizes e Procuradores. In: JOBIM, Nelson; PORTO, Walter Costa (Org.). Legislação eleitoral no Brasil: do século XVI a nossos dias. Brasília: Senado Federal, 1996. v. 1. p. 17-18.

ALVARÁ de 5 de abril de 1618. In: Brasília: Senado Federal, 1996. v. 1. p. 19-20.

BETTELHEIM, Charles. The Transition to Socialist Economy. [S.1.]: The Harvester Press Limited, 1975. Disponível em: http://www.marx2mao.com/Other/TSE68NB.html. Acesso em: 07 jul. 2016.

BATISTA, Flávio Roberto. Crítica da tecnologia dos direitos sociais. São Paulo: Outras Expressões; Dobra Editorial, 2013. (Coleção Direitos e Lutas Sociais)

BIONDI, Pablo. Capitalismo e direitos humanos de solidariedade: elementos para uma crítica. 2015. 359 f. Tese (Doutorado em Direito) - Faculdade de Direito, Universidade de São Paulo, São Paulo.

Os direitos humanos e sociais e o capitalismo: elementos para uma crítica. 2012. 184 f. Dissertação (Mestrado em Direito) - Faculdade de Direito, Universidade de São Paulo.

BRASIL. Código Eleitoral (1932). Decreto $\mathrm{n}^{\mathrm{o}}$ 21.076, de 24 de fevereiro de 1932. In: JOBIM, Nelson; PORTO, Walter Costa (Org.). Legislação eleitoral no Brasil: do século XVI a nossos dias. Brasília: Senado Federal, 1996. v. 2. p. 190-214.

Constituição (1824). Carta de Lei de 25 de março de 1824. Manda observar a Constituição Política do Império, oferecida e jurada por Sua Majestade o Imperador. Dispositivos selecionados pelos organizadores. In: Brasília: Senado Federal, 1996. v. 1. p. 43-52. 
. Constituição (1891). Constituição da República dos Estados Unidos do Brasil, de $\overline{24}$ de fevereiro de 1891. Dispositivos selecionados pelos organizadores. In: . Brasília: Senado Federal, 1996. v. 1. p. 395-400.

. Constituição (1937). Constituição da República dos Estados Unidos do Brasil, de 10 de novembro de 1937. Dispositivos selecionados pelos organizadores. In: . Brasília: Senado Federal, 1996. v. 2. p. 352-359.

. Constituição (1937). Lei Constitucional $n^{\circ}$ 9, de 28 de fevereiro de 1945. In: . Brasília: Senado Federal, 1996. v. 2. p. 362-367.

Constituição (1946). Constituição dos Estados Unidos do Brasil, de 18 de setembro de 1946. Dispositivos selecionados pelos organizadores. In:

Brasília: Senado Federal, 1996. v. 2. p. 427-437.

. Constituição (1967). Emenda Constitucional no 25, de 15 de maio de 1985. Altera dispositivos da Constituição Federal e estabelece outras normas constitucionais de caráter transitório. In: . Brasília: Senado Federal, 1996. v. 3. p. 392-395.

Constituição (1988). Constituição da República Federativa do Brasil, de 5 de outubro de $1988 . \quad$ Disponível em: http://www.planalto.gov.br/ccivil 03/constituicao/constituicaocompilado.htm. Acesso em: 23 nov. 2016.

. Decreto de 7 de março de 1821. Manda proceder à nomeação dos Deputados às Côrtes Portuguezas, dando instrucções a respeito. In: JOBIM, Nelson; PORTO, Walter Costa (Org.). Legislação eleitoral no Brasil: do século XVI a nossos dias. Brasília: Senado Federal, 1996. v. 1. p. 25-33.

Decisão $n^{\circ} 57$ - Reino - de 19 de junho de 1822. Instrucções, a que se refere o Real Decreto de 3 de junho do corrente ano que manda convocar uma Assembléia Geral Constituinte e Legislativa para o Reino do Brasil. In: Brasília: Senado Federal, 1996. v. 1. p. 37-42.

. Decreto de 26 de março de 1824. Manda proceder à eleição dos Deputados e Senadores da Assembléa Geral Legislativa e dos Membros dos Conselhos Geraes das Províncias. In: . Brasília: Senado Federal, 1996. v. 1. p. 53-62. 
Decreto $\mathrm{n}^{\circ} 484$, de 25 de novembro de 1846. Declara como deve avaliar-se a renda liquida em prata, que, na conformidade da Lei Regulamentar das Eleições, deve ter o Cidadão para votar, e ser votado. In: . Brasília: Senado Federal, 1996. v. 1. p. 113.

. Decreto $n^{\circ} 842$, de 19 de setembro de 1855. Altera a Lei de 19 de Agosto de 1846. In: . Brasília: Senado Federal, 1996. v. 1. p. 115-117.

. Decreto $\mathrm{n}^{\mathrm{o}} 3.029$, de 9 de janeiro de 1881. Reforma a legislação eleitoral. In: . Brasília: Senado Federal, 1996. v. 1. p. 213-235.

Decreto $\mathrm{n}^{\circ} 200$ A, de 8 de fevereiro de 1890. Promulga o regulamento eleitoral. In: . Brasília: Senado Federal, 1996. v. 1. p. 364-374.

Decreto $n^{\circ}$ 511, de 23 de junho de 1890. Manda observar o regulamento para a eleição do primeiro Congresso Nacional. In: : Senado Federal, 1996. v. 1. p. 378-388.

Decreto $\mathrm{n}^{\circ} 22.627$, de 7 de abril de 1933. Aprova as instruções para a realização da eleição para a Assembléa Nacional Constituinte. In: : Senado Federal, 1996. v. 2. p. 241-268.

Lei de $1^{\circ}$ de Outubro de 1828. Dá nova forma às Câmaras Municipais, marca suas atribuições, e o processo para a sua eleição, e dos Juizes de Paz. In: Brasília: Senado Federal, 1996. v. 1. p. 69-78.

. Lei no 387, de 19 de agosto de 1846. Regula a maneira de proceder às Eleições de Senadores, Deputados, Membros das Assembléas Provinciaes, Juizes de Paz, e Camaras Municipaes. In: Brasília: Senado Federal, 1996. v. 1. p. 96-112.

Lei $\mathrm{n}^{\mathrm{o}} 35$, de 26 de janeiro de 1892. Estabelece o processo para as eleições federaes. In: Brasília: Senado Federal, 1996. v. 1. p. 405-420.

. Lei $\mathrm{n}^{\circ} 426$, de 7 de dezembro de 1896. Manda observar, nas eleições federaes, o disposto no art. $6^{\circ}$ da Lei $\mathrm{n}^{\mathrm{o}} 248$, de 15 de dezembro de 1894 , sempre que se dê o caso previsto no $\S 2^{\circ}$ do art. 43 da [Lei] de $n^{\circ} 35$, de 26 de janeiro de 1892 , e dá outras providências. In: . Brasília: Senado Federal, 1996. v. 1. p. 466-467. 
. Lei n ${ }^{0} 1.629$, de 15 de novembro de 1904. Reforma a legislação eleitoral, e dá outras providencias. In: . Brasília: Senado Federal, 1996. v. 2. p. 14-35.

Lei $\mathrm{n}^{\mathrm{o}} 2.582$, de 30 de agôsto de 1955. Institui a Cédula Única de Votação. In: . Brasília: Senado Federal, 1996. v. 2. p. 505-507.

. Lei $\mathrm{n}^{\mathrm{o}} 2.982$, de 30 de novembro de 1956. Modifica dispositivos da Lei $\mathrm{n}^{\mathrm{o}} 2.550$, de 25 de julho de 1955, que altera o Código Eleitoral (Lei $\mathrm{n}^{\circ} 1.164$, de 24 de julho de 1950), e dá outras providências. In: . Brasília: Senado Federal, 1996. v. 2. p. $508-510$.

Lei $n^{0} 4.109$, de 27 de julho de 1962. Institui a cédula oficial de votação nas eleições pelo sistema proporcional e dá outras providências. In: Brasília: Senado Federal, 1996. v. 2. p. 524-528.

. Lei no 4.115, de 22 de agôsto de 1962. Introduz alterações na Lei no 4.109, de 27 de julho de 1962, e dá outras providências. In: . Brasília: Senado Federal, 1996. v. 2. p. 529-534.

CARVALHO, José Murilo de. Cidadania no Brasil: o longo caminho. 11. ed. Rio de Janeiro: Civilização Brasileira, 2008.

CHAGAS, Juary. Sociedade de Classe, Direito de Classe: uma perspectiva marxista e atual. São Paulo: Instituto José Luís e Rosa Sundermann, 2011.

CIAFARDINI, Horacio. Capital, Comercio y Capitalismo: A Proposito del Llamado "Capitalismo Comercial". In: ASSADOURIAN, Carlos Sempat et al. Modos de Producción en América Latina. 13. ed. Buenos Aires: Siglo XXI Editores, 2005. p. 111134. (Biblioteca del pensamento socialista: serie ensayos críticos).

CORREIA, Marcus Orione Gonçalves. Que Fazer. In: ANDRADE, José Maria Arruda de; COSTA, José Augusto Fontoura; MATSUO, Alexandra Mery Hansen. Direito: teoria e experiência: estudos em homenagem a Eros Roberto Grau. São Paulo: Malheiros, 2013. p. 530-560.

COSTA, Iraci del Nero. A formação das economias periféricas sob a ótica da História Econômica Geral. In: COSTA, Iraci del Nero; PIRES, Julio Manuel (Org.). O capital escravista-mercantil e a escravidão nas Américas. São Paulo: FAPESP, 2010a. p. 63-68. 
Algumas opiniões sobre a categoria "modo de produção". In: . São

Paulo: FAPESP, 2010b. p. 69-79.

. Repensando o modelo interpretativo de Caio Prado Júnior. In:

São Paulo: FAPESP, 2010c. p. 81-125

Sobre a não existência de modos de produção coloniais. In:

. São

Paulo: FAPESP, 2010d. p. 59-62.

COSTA, Iraci del Nero; PIRES, Julio Manuel. Causas imediatas da superação do capital escravista-mercantil. In: São Paulo: FAPESP, 2010a. p. 33-58.

. O capital escravista-mercantil. In: . São Paulo: FAPESP, 2010b. p. $7-32$.

EDELMAN, Bernard. A legalização da classe operária. Tradução: Marcus Orione Gonçalves Correia et al. São Paulo: Boitempo, 2016.

O direito captado pela fotografia: elementos para uma teoria marxista do direito. Coimbra: Centelha, 1976.

FAORO, Raymundo. Os donos do poder: formação do patronato político brasileiro. 6. ed. Porto Alegre; Rio de Janeiro: Globo, 1984. v. 1.

5 ed. Porto Alegre; Rio de Janeiro: Globo, 1979. v. 2.

FERNANDES, Florestan. A Revolução Burguesa no Brasil: ensaio de interpretação sociológica. São Paulo: Globo, 2006.

FERREIRA, Manoel Rodrigues. A evolução do sistema eleitoral brasileiro. Brasília: TSE, Secretaria de Documentação e Informação, 2005.

FLORENTINO, Manolo; FRAGOSO, João. O arcaísmo como projeto: mercado atlântico, sociedade agrária e elite mercantil no Rio de Janeiro, c. 1790 - c. 1840. Rio de Janeiro: Diadorim, 1993. 
FURTADO, Celso. Formação econômica do Brasil. 7. ed. São Paulo: Cia. Editora Nacional, 1967.

GORENDER, Jacob. A Burguesia Brasileira. São Paulo: Brasiliense, 1981. (Coleção Tudo é História)

. A Revolução Burguesa e os Comunistas. In: D’INCAO, Maria Angela (Org.). O saber militante: ensaios sobre Florestan Fernandes. Rio de Janeiro: Paz e Terra; São Paulo: UNESP, 1987. p. 250-259.

O conceito de modo de produção e a pesquisa histórica. In: LAPA, J. R. do Amaral (Org.). Modos de produção e realidade brasileira. Petrópolis: Vozes, 1980. p. 43-65.

O escravismo colonial. São Paulo: Ática, 1978. (Ensaios nº 29)

KASHIURA JÚNIOR, Celso Naoto. Crítica da igualdade jurídica: contribuição ao pensamento jurídico marxista. São Paulo: Quartier Latin, 2009.

Dialética e forma jurídica: considerações acerca do método de Pachukanis. In: NAVES, Márcio Bilharinho (Org.). O discreto charme do direito burguês: ensaios sobre Pachukanis. Campinas: Unicamp, Instituto de Filosofia e Ciências Humanas, 2009. p. 53 77. (Coleção Ideias n ${ }^{\circ} 8$ )

. Duas formas absurdas: uma defesa da especificidade histórica da mercadoria e do sujeito de direito. In: . Campinas: Unicamp, Instituto de Filosofia e Ciências Humanas, 2009. p. 117-133. (Coleção Ideias no $\left.{ }^{8}\right)$

Sujeito de direito e capitalismo. 2012. 177 f. Tese (Doutorado em Direito) Faculdade de Direito, Universidade de São Paulo, São Paulo.

LOUREIRO, Lourenço Trigo de. Instituições de direito civil brasileiro. Ed. fac-sim. Brasília: Senado Federal, Conselho Editoral; Superior Tribunal de Justiça, 2004. 
MAESTRI, Mário. Jacob Gorender. In: PERICÁS, Luiz Bernardo; SECCO, Lincoln Ferreira (Org.). Intérpretes do Brasil: clássicos, rebeldes e renegados. São Paulo: Boitempo, 2014. p. 253-273.

MARX, Karl. Grundrisse: manuscritos econômicos de 1857-1858: esboços da crítica da economia política. São Paulo: Boitempo, 2011.

O Capital: crítica da economia política: o processo de produção do capital. São Paulo: Boitempo, 2013. Livro I.

O Capital: crítica da economia política: o processo global da produção capitalista. 2. ed. São Paulo: Nova Cultural, 1986. v. III. Livro Terceiro. Tomo 2. Parte Segunda. (Os Economistas)

MELlO, João Cardoso de. O Capitalismo Tardio. 8. ed. São Paulo: Brasiliense, 1991.

MIAILLE, Michel. Introdução crítica ao direito. 3. ed. Lisboa: Estampa, 2005.

NAVES, Márcio Bilharinho. A questão do Direito em Marx. São Paulo: Outras Expressões; Dobra Universitário, 2014. (Coleção Direitos e Lutas Sociais)

Marxismo e Direito: um estudo sobre Pachukanis. São Paulo: Boitempo, 2008.

NICOLAU, Jairo. Eleições no Brasil: do Império aos Dias Atuais. Rio de Janeiro: Zahar, 2012.

. História do Voto no Brasil. Rio de Janeiro: Zahar, 2002.

NOVAIS, Fernando A. Portugal e Brasil na Crise do Antigo Sistema Colonial (17771808). São Paulo: Hucitec, 1989.

OLIVEIRA, Francisco de. Crítica à razão dualista / O Ornitorrinco. São Paulo: Boitempo, 2008.

ORDENAÇÕES Filipinas. Livro I. Título LXVII. Em que modo se fará a eleição dos Juizes, Véreadores, Almotacés e outros Oficiaes. Título LXVIII. Dos Almotacés. In: 
JOBIM, Nelson; PORTO, Walter Costa (Org.). Legislação eleitoral no Brasil: do século XVI a nossos dias. Brasília: Senado Federal, 1996. v. 1. p. 12-16.

ORDENAÇÕES Manuelinas. Título XLV. Em que modo fe fará a eleiçam dos juizes, e Vereadores, e outros Officiaes. In: . Brasília: Senado Federal, 1996. v. 1. p. 9-11.

PACHUKANIS, E. B. A teoria marxista do direito e a construção do socialismo. In: NAVES, Márcio Bilharinho (Org.). O discreto charme do direito burguês: ensaios sobre Pachukanis. Campinas: Unicamp, Instituto de Filosofia e Ciências Humanas, 2009. p. 137149. (Coleção Ideias no 8)

Teoria Geral do Direito e Marxismo. São Paulo: Acadêmica, 1988.

PERICÁS, Luiz Bernardo; WIDER, Maria Célia. Caio Prado Júnior. In: PERICÁS, Luiz Bernardo; SECCO, Lincoln Ferreira (Org.). Intérpretes do Brasil: clássicos, rebeldes e renegados. São Paulo: Boitempo, 2014. p. 193-214.

PORTO, José da Costa. As eleições para os "senados da câmara". In: AMADO, Gilberto et al. A cidadania no Brasil II: o voto. Brasília: Senado Federal, Ministério da Ciência e Tecnologia, Centro de Estudos Estratégicos, 2002. v. VIII. p. 9-16. (Leituras sobre a cidadania)

PORTO, Walter Costa. O Voto no Brasil: da Colônia à $6^{a}$ República. 2. ed. rev. Rio de Janeiro: Topbooks, 2002.

PRADO JÚNIOR, Caio. A Revolução Brasileira: perspectivas em 1977. São Paulo: Brasiliense, 1987.

. Evolução Política do Brasil e Outros Estudos. São Paulo: Brasiliense, 1969

. Formação do Brasil Contemporâneo: Colônia. São Paulo: Brasiliense, 1963.

Histórica Econômica do Brasil. São Paulo: Brasiliense, 1974.

REGIMENTO de 10 de maio de 1640. De como se farão as eleições de Vereadores, Procuradores, e Officiaes das Camaras destes Reinos. In: JOBIM, Nelson; PORTO, Walter 
Costa (Org.). Legislação eleitoral no Brasil: do século XVI a nossos dias. Brasília: Senado Federal, 1996. v. 1. p. 21-23.

RICUPERO, Bernardo. Caio Prado Jr. e a nacionalização do marxismo no Brasil. São Paulo: Departamento de Ciência Política da Universidade de São Paulo; FAPESP; Ed. 34, 2000 .

SAES, Décio. A Formação do Estado Burguês no Brasil (1888-1891). Rio de Janeiro: Paz e Terra, 1985.

A participação das massas brasileiras na revolução anti-escravista e antimonárquica (1888-1891). Revista Brasileira de História: revista da Associação Nacional de História, São Paulo, v. 1, p. 13-24, 1981.

Direitos Sociais e Transição para o Capitalismo: o caso da Primeira República Brasileira (1889-1930). Estudos de Sociologia, Araraquara, v. 11, n. 20, p. 23-51, 2006.

República do Capital: Capitalismo e Processo Político no Brasil. São Paulo: Boitempo, 2001.

SECCO, Lincoln. Caio Prado Júnior: o sentido da revolução. São Paulo: Boitempo, 2008. (Pauliceia)

SOUZA, Francisco Belisário Soares de. As Eleições no Império. In: AMADO, Gilberto et al. A cidadania no Brasil II: o voto. Brasília: Senado Federal, Ministério da Ciência e Tecnologia, Centro de Estudos Estratégicos, 2002. v. VIII. p. 17-39. (Leituras sobre a cidadania)

SOUZA, João Paulo A. Entre o sentido da colonização e o arcaísmo como projeto: a superação de um dilema através do conceito de capital escravista-mercantil. In: COSTA, Iraci del Nero; PIRES, Julio Manuel (Org.). O capital escravista-mercantil e a escravidão nas Américas. São Paulo: FAPESP, 2010. p. 126-171.

TEIXEIRA, Rodrigues Alves. Capital e colonização: a constituição da periferia do sistema capitalista mundial. In: . São Paulo: FAPESP, 2010. p. 172-254.

TAVARES, Maria Conceição. Da substituição de importações ao capitalismo financeiro: ensaios sobre economia brasileira. Rio de Janeiro: Zahar, 1972. 
VIANA, Oliveira. Instituições Políticas Brasileiras. Brasília: Conselho Editorial do Senado Federal, 1999. (Coleção Biblioteca Básica Brasileira) 